\title{
AVALIAÇÃO DA PRESENÇA DO ACOMPANHANTE NO PARTO E PUERPÉRIO EM MATERNIDADE PÚBLICA
}

Thabita Helena Vaz', Liane Fuhr Pivatto²

Enfermeira. Residente em Atenção Hospitalar. Universidade Federal do Paraná. Curitiba-PR-Brasil.

Enfermeira. Mestre em Distúrbio da Comunicação. Universidade Federal do Paraná. Curitiba-PR-Brasil.

RESUMO: Estudo descritivo quantitativo com o objetivo de avaliar a opinião de puérperas sobre a experiência da presença do acompanhante, no processo do parto e puerpério, em uma maternidade pública, referência para gestação de alto risco, do Estado do Paraná-Brasil. A coleta de dados ocorreu entre agosto e setembro de 2012 com 105 puérperas, a partir de questionário semiestruturado. A presença do acompanhante foi considerada positiva e as tarefas por ele realizadas proporcionaram à puérpera segurança, especialmente pelo cuidado com ela e o bebê. Destacou-se que as usuárias querem ter acompanhante, independentemente das condições estruturais da instituição.

DESCRITORES: Enfermagem obstétrica; Humanização do parto; Alojamento conjunto.

\section{EVALUATION OF THE PRESENCE OF THE COMPANION DURING BIRTH AND THE PUERPERIUM IN A PUBLIC MATERNITY UNIT}

\begin{abstract}
This descriptive quantitative study aimed to evaluate puerperas' opinions regarding experiencing the presence of the companion in the process of birth and puerperium, in a public maternity unit, a center of excellence for high risk pregnancies, in the State of Paraná. Data collection occurred between August and September 2012 with 105 puerperas, using a semistructured questionnaire. The presence of the companion was considered positive, and the tasks he undertook provided the puerpera with security, especially for care for her and the baby. It stood out that the service users wish to have a companion, regardless of the institution's structural conditions.
\end{abstract}

DESCRIPTORS: Obstetric nursing; Humanization of birth; Maternity ward.

\section{EVALUACIÓN DE LA PRESENCIA DEL ACOMPAÑANTE EN EL PARTO Y PUERPÉRIO EN MATERNIDAD PÚBLICA}

RESUMEN: Estudio descriptivo cuantitativo cuyo objetivo fue evaluar la opinión de puérperas sobre la experiencia de la presencia del acompañante, en el proceso del parto y puerpério, en una maternidad pública, referencia para gravidez de alto riesgo, del Estado de Paraná. Los datos fueron obtenidos entre agosto y septiembre de 2012 con 105 puérperas, con base en un cuestionario semiestructurado. La presencia del acompañante fue considerada positiva y las tareas por él realizadas proporcionaron a la puérpera seguridad, especialmente en razón del cuidado con ella y el bebé. Se destaca que las usuarias quieren un acompañante, independientemente de las condiciones estructurales de la institución.

DESCRIPTORES: Enfermería obstétrica; Humanización del parto; Alojamiento conjunto. 


\section{INTRODUÇÃO}

Até o final dos anos 1990, muitas das maternidades públicas do Brasil enfatizavam a evolução, a observação e o monitoramento de complicações no processo de trabalho de parto, excluindo a participação da família e outros aspectos importantes do contexto social( ${ }^{(1)}$. As maternidades do Sistema Único de Saúde (SUS), em geral, passaram por diversas transformações no que diz respeito à assistência; isso ocorreu, especialmente, quanto ao direito da permanência de um acompanhante junto à mulher, durante as 24 horas em que ocorre o processo do parto, nascimento e puerpério, constituindo-se em diferencial e potencial para proporcionar segurança e conforto( ${ }^{(2)}$.

Esta recomendação se deu a partir da conferência sobre Tecnologias Apropriadas para o Nascimento e Parto, em 1985, da Organização Mundial da Saúde, a qual estabeleceu que

O bem-estar da nova mãe deve ser assegurado através do livre acesso de um membro da família, de sua escolha, ao parto, nascimento e durante o período puerperal. Além disso, a equipe de saúde deve proporcionar-lhe apoio emocional ${ }^{(3: 436-7)}$.

No Brasil, o direito à presença do acompanhante no parto foi regulamentado em 2005. A partir de então, as maternidades receberam a incumbência de incluir o novo integrante, providenciando o redimensionamento do espaço físico e preparando a equipe para que sua presença fosse potencializada ${ }^{(4)}$. Neste contexto, a Resolução da Diretoria Colegiada da Agência Nacional de Vigilância Sanitária n. 36 de três de junho de $2008^{(5)}$ apresenta as atribuições do acompanhante que, basicamente, referemse ao apoio à parturiente e à segurança no processo do parto e nascimento, influenciando positivamente no processo de trabalho da equipe de saúde.

Estudo aponta que a presença do acompanhante no processo de nascimento propicia a humanização da assistência e desafia a prática; para a parturiente transmite segurança, conforto e vínculo com o seu meio familiar; à equipe, instiga a reflexão da forma como se desenvolve a prática obstétrica; para a instituição proporciona a avaliação de sua forma de gestão da assistência à saúde ${ }^{(6)}$. Não existem, portanto, justificativas para que as mulheres permaneçam sozinhas neste momento. Evidências científicas têm comprovado que o apoio à mulher no momento do parto melhora as condições de nascimento, diminuindo os índices de cesarianas, de partos complicados e da duração do trabalho de parto, bem como a ocorrência de depressão pós-parto e o uso de medicações para o alívio da dor. O apoio possibilita à mulher a percepção do parto como experiência positiva na vida, fortalecendo os vínculos entre acompanhante, mãe e bebê, com efeitos que geralmente se repercutem no aumento da duração do tempo de aleitamento materno ${ }^{(4)}$.

No entanto, apesar dos benefícios científicos demonstrados e da garantia legal, algumas instituições de saúde alegam dificuldades em estrutura física e recursos humanos para se adequarem à inserção do acompanhante ${ }^{(7)}$. Exemplo disso é o que apresenta a ouvidoria da Rede Cegonha, estratégia do Ministério da Saúde, operacionalizada pelo SUS, fundamentada nos princípios de humanização e assistência. Os dados coletados entre maio e outubro de 2012 indicam que $64 \%$ das 54 mil mulheres entrevistadas responderam que não tiverem direito ao acompanhante. Situação semelhante foi constatada pelo SUS, quando $49,7 \%$ das entrevistadas afirmaram não terem podido se beneficiar deste direito ${ }^{(8)}$.

Considerando ser essencial a presença de um acompanhante no momento do parto, quando fosse desejo da mulher, por contribuir com a autoconfiança da mãe e os cuidados com a puérpera e o bebê, estabeleceu-se o seguinte objetivo: avaliar a opinião das puérperas sobre a experiência da presença do acompanhante no processo do parto e puerpério.

\section{MÉTODO}

Trata-se de um estudo quantitativo descritivo, com puérperas internadas no Alojamento Conjunto de uma maternidade de um hospital universitário, referência para gestação de alto risco no Estado do Paraná-Brasil, que mantém o titulo Hospital Amigo da Criança desde 1995. O serviço da maternidade conta com 28 leitos ativos, sendo 16 leitos para o acompanhamento 
conjunto, seis leitos para gestação de risco e seis para as puérperas cujos recém-nascidos se encontram internados na UTI Neonatal. Atende em média 200 partos/mês.

A coleta de dados foi realizada no Alojamento Conjunto, a partir de convite a todas as puérperas da unidade, antes da alta hospitalar, durante os meses de agosto e setembro de 2012. Foram adotados os seguintes critérios de inclusão: ser puérpera maior de idade e formalizar a participação, após ter sido informada sobre os objetivos da pesquisa.

No momento da pesquisa, a lei do acompanhante estava sendo implementada na maternidade; atualmente o serviço conta com duas funcionárias responsáveis pelo acolhimento desses acompanhantes.

A coleta dos dados ocorreu mediante questionário semiestruturado que utilizou dois grupos de perguntas: no primeiro, referente à identificação das participantes do estudo, os itens referiram-se às variáveis socioeconômicas, profissionais, antecedentes obstétricos, tipo de parto e idade gestacional. O segundo, sobre questões técnicas, tratou de dados informativos do direito de ter acompanhante, das atribuições do acompanhante, esclarecimentos sobre as funções do acompanhante na maternidade e seu desempenho, bem como das dificuldades encontradas durante o período de internamento e sugestões para solucioná-las. Os resultados foram organizados sob aspecto do cuidado e psicossocial.

A pesquisa atendeu aos aspectos éticos e foi aprovada por Comitê de Ética em Pesquisa sob o Parecer n. 43645.

\section{RESULTADOS}

Participaram da pesquisa 105 puérperas, dentre elas $47,9 \%$ tinham idade entre 25 e 35 anos e $58 \%$ estudaram até o ensino médio. A grande maioria (60\%) era da capital paranaense; trabalhavam em casa (42\%) e, entre as assalariadas, $40 \%$ tinham renda média de dois salários mínimos. Das 105 puérperas; 60\% tiveram parto cesariana, $61 \%$ dos bebês nasceram com gestação a termo e 50\% realizaram o prénatal na maternidade da pesquisa.

Quanto aos acompanhantes, eles estiveram presentes em algum momento do processo do parto e puerpério de $88 \%$ das puérperas. Em $62,3 \%$ dos casos era o esposo. Entre aquelas que não tiveram acompanhantes constituíram as seguintes causas: a falta de alguém para acompanhar o parto; parto de emergência; a pessoa convidada não aceitou ser acompanhante.

Muitas puérperas $(48,2 \%)$ relataram ter recebido a informação da equipe de enfermagem sobre o direito de ter um acompanhante no parto.

Verificou-se que a presença do acompanhante foi considerada positiva, uma vez que proporcionou segurança, dividiu a emoção do parto e ajudou nos cuidados com a puérpera e o bebê (Tabela 1). Especificamente no pré-parto, as participantes da pesquisa opinaram sobre quais seriam as atribuições dos acompanhantes ao longo do internamento da mulher no Alojamento Conjunto. Observou-se que as puérperas valorizaram as ações que envolvem o cuidado com o bebê e o cuidado com elas. Entre as atribuições relacionadas aos aspectos psicossociais e afetivos priorizaram o conforto afetivo (Tabela 2).

A maioria das atividades realizadas pelo acompanhante durante a permanência na maternidade esteve relacionada ao cuidado com o bebê e à transmissão de segurança, no âmbito dos aspectos psicossociais e emocionais, como mostra a Tabela 3. Salienta-se que as expectativas da puérpera foram superadas, pois as atribuições esperadas por ela foram maiores quando relacionou as atividades que o acompanhante realizou.

Foram diversas dificuldades elencadas pelas participantes da pesquisa, sendo relacionamento com a equipe de saúde a maior dificuldade encontrada (Tabela 4). Em muitos aspectos as questões gerenciais, dentre elas as inter-relações profissionais, aparecem com maior frequência. Este fato é preocupante em unidade de referência em hospital escola.

Nas sugestões apresentadas pelas puérperas para melhorar a assistência (Tabela 4) pode-se observar que os usuários esperam da equipe de saúde maior atenção, além da melhora da acomodação dos acompanhantes e da ampliação dos horários de visita. 
Tabela 1 -Opiniãodas puérperas em relaçãoà experiência de ter acompanhante. Curitiba-PR-Brasil, 2012

\begin{tabular}{lcc}
\hline Psicossocial & $\mathbf{n}$ & $\mathbf{\%}$ \\
\hline Oferecer segurança & 92 & 33,95 \\
\hline Dividir a emoção & 20 & 7,38 \\
\hline Passar força psicológica & 16 & 5,90 \\
\hline $\begin{array}{l}\text { Contar com a presença } \\
\text { do pai do bebê }\end{array}$ & 15 & 5,54 \\
\hline Acalmar & 15 & 5,54 \\
\hline Apoiar & 13 & 4,80 \\
\hline Incentivar/encorajar & 11 & 4,06 \\
\hline Conversar & 08 & 2,95 \\
\hline Amenizar a dor & 07 & 2,58 \\
\hline $\begin{array}{l}\text { Compartilhar com o } \\
\text { marido o processo }\end{array}$ & 07 & 2,58 \\
\hline $\begin{array}{l}\text { Acalmar o medo do } \\
\text { hospital }\end{array}$ & 06 & 2,21 \\
\hline Cuidado & $\mathbf{n}$ & $\mathbf{\%}$ \\
\hline $\begin{array}{l}\text { Ajudar nos cuidados à } \\
\text { mulher }\end{array}$ & 24 & 8,86 \\
\hline Ajudar a cuidar do bebê & 19 & 7,01 \\
\hline Ajudar no geral & 11 & 4,06 \\
\hline Ajudar na hora do parto & 07 & 2,58 \\
\hline Total & $\mathbf{2 7 1}$ & $\mathbf{1 0 0}$ \\
\hline & & \\
\hline
\end{tabular}

Tabela 2 - Opinião das puérperas sobre as possíveis atribuições do acompanhante. Curitiba-PR-Brasil, 2012

\begin{tabular}{lcc}
\hline Cuidado & $\mathbf{n}$ & $\mathbf{\%}$ \\
\hline $\begin{array}{l}\text { Ajudar a cuidar da } \\
\text { mulher }\end{array}$ & 49 & 19,37 \\
\hline Ajudar em geral & 26 & 10,28 \\
\hline $\begin{array}{l}\text { Promover vínculo com } \\
\text { o bebê }\end{array}$ & 09 & 3,56 \\
\hline $\begin{array}{l}\text { Cuidar do bebê para } \\
\text { não ser trocado }\end{array}$ & 06 & 2,37 \\
\hline Psicossocial & $\mathbf{n}$ & $\mathbf{\%}$ \\
\hline $\begin{array}{l}\text { Oferecer apoio } \\
\text { psicológico e afetivo }\end{array}$ & 42 & 16,6 \\
\hline Passar segurança & 35 & 13,83 \\
\hline Conversar/acalmar & 31 & 12,25 \\
\hline Ter companhia & 30 & 11,86 \\
\hline Passar confiança & 14 & 5,53 \\
\hline Ter carinho & 11 & 4,35 \\
\hline Total & $\mathbf{2 5 3}$ & $\mathbf{1 0 0}$ \\
\hline
\end{tabular}

Tabela 3 - Atividades desenvolvidas pelo acompanhante, segundo a opinião das puérperas. Curitiba-PR-Brasil, 2012

\begin{tabular}{lcc}
\hline Cuidado & $\mathbf{n}$ & $\mathbf{\%}$ \\
\hline $\begin{array}{l}\text { Ajudar a cuidar do } \\
\text { bebê }\end{array}$ & 51 & 15,05 \\
\hline Ajudar a cuidar de mim & 43 & 12,68 \\
\hline Pegar o bebê no colo & 23 & 6,78 \\
\hline $\begin{array}{l}\text { Cuidar do bebê para a } \\
\text { puérpera descansar }\end{array}$ & 21 & 6,19 \\
\hline Ajudar em geral & 20 & 5,89 \\
\hline $\begin{array}{l}\text { Auxiliar em } \\
\text { procedimentos: bola/ } \\
\text { cavalinho/massagem }\end{array}$ & 09 & 2,66 \\
\hline Fazer tudo que se pedia & 09 & 2,66 \\
\hline Ajudar a amamentar & 04 & 1,18 \\
\hline Psicossocial & $\mathbf{n}$ & $\mathbf{\%}$ \\
\hline Passar segurança & 40 & 11,80 \\
\hline Segurar a mão & 27 & 7,96 \\
\hline Conversar & 18 & 5,31 \\
\hline Apoiar & 17 & 5,01 \\
\hline Passar incentivo & 15 & 4,42 \\
\hline Dar atenção & 10 & 2,95 \\
\hline $\begin{array}{l}\text { Demonstrar } \\
\text { preocupação }\end{array}$ & 09 & 2,66 \\
\hline Passar carinho & 09 & 2,66 \\
\hline Ter paciência & 07 & 2,06 \\
\hline Ficar junto & 07 & 2,06 \\
\hline Total & $\mathbf{3 3 9}$ & $\mathbf{1 0 0}$ \\
\hline & & \\
\hline
\end{tabular}


Tabela 4 - Dificuldades encontradas no Alojamento Conjunto e sugestões das puérperas. Curitiba-PR-Brasil, 2012

\begin{tabular}{|c|c|c|}
\hline Dificuldades encontradas & $\mathbf{n}$ & $\%$ \\
\hline $\begin{array}{l}\text { Necessidade de melhor relacionamento com a } \\
\text { equipe de saúde }\end{array}$ & 47 & 51,09 \\
\hline As copeiras precisariam ter mais paciência & 07 & 7,61 \\
\hline Sentir medo & 06 & 6,52 \\
\hline $\begin{array}{l}\text { Falta de permissão para o acompanhante assistir o } \\
\text { parto }\end{array}$ & 06 & 6,52 \\
\hline Ter maior flexibilidade no horário de visita & 06 & 6,52 \\
\hline Falta de privacidade & 05 & 5,43 \\
\hline Ausência do médico no Centro Obstétrico & 05 & 5,43 \\
\hline Melhorar a alimentação para o acompanhante & 04 & 4,35 \\
\hline $\begin{array}{l}\text { O acompanhante não pode ver o bebê logo após } \\
\text { o parto }\end{array}$ & 03 & 3,26 \\
\hline O acompanhante não pode ficar à noite & 02 & 2,18 \\
\hline Realizar o primeiro banho sem o pai do bebê & 01 & 1,09 \\
\hline Total & 92 & 100 \\
\hline Sugestões & $\mathbf{n}$ & $\%$ \\
\hline Maior atenção ao usuário & 69 & 52,27 \\
\hline Acomodação para os acompanhantes & 17 & 12,87 \\
\hline Ampliar os horários de visita & 11 & 8,33 \\
\hline Melhorar o serviço das copeiras & 07 & 5,30 \\
\hline Falar a linguagem do usuário & 05 & 3,79 \\
\hline Melhorar a comida & 05 & 3,79 \\
\hline Informações aos acompanhantes & 04 & 3,03 \\
\hline Pernoite do pai do bebê & 04 & 3,03 \\
\hline Visita dos irmãos menores & 03 & 2,27 \\
\hline Não internar pacientes graves com parturientes & 02 & 1,52 \\
\hline Banheiro para o acompanhante mais perto & 01 & 0,76 \\
\hline Perguntar sugestões para as pacientes & 01 & 0,76 \\
\hline Auxiliar melhor as mães & 01 & 0,76 \\
\hline $\begin{array}{l}\text { Alguém da equipe de enfermagem ficar junto com } \\
\text { quem não tem acompanhante }\end{array}$ & 01 & 0,76 \\
\hline Chamar o acompanhante para participar do parto & 01 & 0,76 \\
\hline Total & 132 & 100 \\
\hline
\end{tabular}




\section{DISCUSSÃO}

Os resultados deste estudo revelam que a maioria das puérperas pôde contar com um acompanhante no parto, sendo o pai do bebê o mais comum. Outros estudos ${ }^{(9-10)}$ demonstraram que a maioria dos acompanhantes era do sexo feminino, as mães das puérperas, bem como revelam maior participação masculina no nascimento. Isto indica que o homem se mostra não somente acessível para cumprir um direito amparado pela Lei ${ }^{(11)}$, mas também deseja inserir-se no contexto como parte importante do processo $^{(12)}$. A proporção de pais acompanhantes, em algum momento do processo do parto neste estudo, é considerada relevante e um diferencial no acolhimento humano, e não somente nos aspectos técnicos da assistência ao parto.

Quase a metade das puérperas $(48,2 \%)$ ficou sabendo pela equipe de enfermagem que tinha direito a ter um acompanhante no parto. A obrigação das instituições de saúde é garantir informações sobre o direito da mulher em ter acompanhante durante o parto e promover a sensibilização dos profissionais de saúde a respeito do cuidado humanizado ${ }^{(5)}$. Constatouse no presente estudo e em outro semelhante ${ }^{(13)}$ que a equipe de enfermagem apoia e incentiva a inserção do acompanhante no parto. Isto pode ser atribuído ao conhecimento que estes profissionais têm sobre o direito do acompanhante no parto e a implantação do Projeto de Acolhimento ao Acompanhante.

As puérperas consideraram positiva a presença do acompanhante, porque proporcionou segurança, dividiu a emoção do parto e ajudou nos cuidados com elas e os bebês. Este aspecto é relevante e significativo e confirma outras pesquisas ${ }^{(14-15)}$ voltadas à presença do acompanhante no processo do parto. Esta pesquisa demonstrou ser a segurança o aspecto mais lembrado pelas mulheres dentre as atribuições do acompanhante, pois esta associada à necessidade de compartilhar medos e anseios com alguém de presença constante e conhecida, durante todo o processo.

Em outro aspecto, a experiência de ter um acompanhante foi considerada positiva, porque auxilia nos cuidados diretos à puérpera e ao bebê. Esta constatação lembra estudos semelhantes ${ }^{(16-17)}$, nos quais de acordo com os quais, o auxílio nas tarefas é contribuição importante do acompanhante, pois representa uma ação de envolvimento afetivo com o outro.

As puérperas consideram que as atribuições do acompanhante devem se relacionar ao cuidado direto com o bebê e com ela, além de ser voltada à segurança e ao conforto. Do mesmo modo, pesquisas qualitativas ${ }^{(18-19)}$ mostram que o acompanhante interagiu e participou do puerpério, dedicando atenção à companheira, interesse em participar dos cuidados ao recém-nascido e com a puérpera. Constata-se ${ }^{(9)}$, também, que a participação do acompanhante é ancorada no apoio emocional, como maior expressão, por transmitir à parturiente maior segurança e conforto. Corroboram com estes achados outros resultados ${ }^{(17-18)}$ que salientam ter sido significativo o interesse dos acompanhantes na participação de atividades inerentes a puérpera e ao recém-nascido.

Enfim, os principais objetivos do acompanhante segundo literaturas ${ }^{(2,19)}$ são tranquilizar a mulher no parto, proporcionando segurança e auxiliando nos cuidados a ela relacionados, como fazer massagens, segurar a mão e cuidar do bebê. Estas práticas são benéficas e devem ser encorajadas por estarem associadas à diminuição de procedimentos desnecessários durante o processo do parto. Em outro estudo ${ }^{(20)}$ demonstrase que, mesmo permanecendo em silêncio no decorrer do processo do parto, alguns pais estão convictos de que sua presença é importante, pois oferecem o apoio emocional, transmitem segurança e gestos de carinho.

Em relação às dificuldades dos usuários e às sugestões para a melhoria do serviço, verificou-se que a equipe de saúde precisa estar mais atenta às necessidades das puérperas e seus acompanhantes. Afinal, a humanização no processo do parto na maioria das vezes é negligenciada e requer atenção ao operar os processos de trabalho em saúde, de forma a atender a todos que procuram os serviços de saúde, ou seja, ouvindo seus pedidos e assumindo no serviço uma postura capaz de acolher, escutar e dar respostas mais adequadas ${ }^{(21)}$.

\section{CONCLUSÕES}

Esta pesquisa possibilitou conhecer a opinião de puérperas atendidas em um Alojamento Conjunto antes da alta hospitalar. As opiniões manifestadas 
pelas mulheres quanto à presença positiva do acompanhante tornam-se interessantes pois indicam com propriedade que valorizam a segurança, o conforto e os cuidados diretos com elas e com os recém-nascidos. Considerandose, também, que o acompanhante no parto já faz parte da rotina da maternidade, realizando atividades voltadas ao recém-nascido e à mulher, conclui-se que as usuárias desejam ter acompanhante, independentemente das condições estruturais da instituição.

Sugere-se, portanto, que sejam realizadas atividades de reflexão, planejamento e prática por parte da equipe de saúde sobre os direitos e os benefícios do acompanhante no parto, possibilitando cada vez mais o acesso aos direitos conquistados legalmente. Recomendase, também, que outros estudos sejam realizados sobre o tema, com destaque para a verificação de como as equipes de enfermagem estão procedendo quanto à informação dos direitos garantidos às famílias no período pré-natal.

\section{REFERÊNCIAS}

1. Matos GC, Escobal AP, Soares MC, Harter J, Gonzales RIC. A trajetória histórica das políticas de atenção ao parto no Brasil: uma revisão integrativa. Rev. enferm. UFPE. 2013;(n. esp)7:870-8.

2. Frutuoso LD, Brüggemann OM. Conhecimento sobre a Lei 11.108/2005 e a experiência dos acompanhantes junto à mulher no Centro Obstétrico. Texto Contexto Enferm. 2013;22(4):909-17.

3. World Health Organization (WHO). Appropriate technology for birth. Lancet. 1985;2(8452):436-7.

4. Ministério da Saúde (BR). Secretaria de Atenção à Saúde. Núcleo Técnico da Política Nacional de Humanização. Humaniza SUS: Visita aberta e direito ao acompanhante. Brasília, 2007.

5. Agência Nacional de Vigilância Sanitária - ANVISA. Resolução da Diretoria Colegiada (RDC) n. 36, de 3 de junho de 2008. Dispõe sobre Regulamento Técnico para Funcionamento dos Serviços de Atenção Obstétrica e Neonatal [Internet] [acesso em 28 abr 2013]. Disponível: http://www.anvisa.gov.br/hotsite/ segurancadopaciente/documentos/rdcs/RDC\%20 N\%C2\%BA\%2036-2008.pdf

6. Paz LS, Fensterseifer LM. Equipe de enfermagem e o acompanhamento no parto em um hospital público de Porto Alegre. Rev. Interdiscipl. NOVAFAPI. 2011;4(1):9-13.

7. Monticelli M, Aires LCP, Volkmer C, Bruggmann
OM. Inserção e atuação do acompanhante no alojamento conjunto de uma maternidade-escola. In: 16.0 SENPE - Ciência da Enfermagem em Tempos de Interdisciplinaridade, 2011. Campo Grande (MS): ABEn; 2003.

8. Brasil. Portal Brasil. Mais de 52 mil mães que tiveram filhos pelo SUS avaliaram atendimento. Portal Brasil 2012 [Internet] [acesso em 11 agosto 2014]. Disponível: http://www.brasil.gov.br/saude/2012/10/mais-de52-mil-maes-que-tiveram-filho-pelo-sus-avaliaramatendimento

9. Nakano MAS, Silva LA, Beleza ACS, Stefanello J, Gomes FA. O suporte durante o processo de parturição: a visão do acompanhante. Acta Paul. Enferm. [Internet] 2007;20(2) [acesso em 17 mar 2013]. Disponível: http://dx.doi.org/10.1590/S010321002007000200004

10. Dodou HD, Rodrigues DP, Guerreiro EM, Guedes MVC, Lago PN, Mesquita NS. A contribuição do acompanhante para humanização do parto e nascimento: percepção de puérperas. Esc. Anna Nery. 2014;18(2):262-9.

11. Lei n. 11.108 de 07 de abril de 2005. Altera a Lei n. 8.080, de 19 de setembro de 1990, para garantir às parturientes o direito à presença de acompanhante durante o trabalho de parto, parto e pós-parto imediato, no âmbito do Sistema Único de Saúde SUS. Diário Oficial da República Federativa do Brasil, Brasília (DF), 8 abr 2005: Seção 1: 1.

12. Gonzalez AD, Fernandes ES, Silva EF, Rabelo M, Souza SRRK. A percepção do acompanhante no processo do nascimento. Cogitare enferm. [Internet] 2012;17(2) [acesso em 23 out 2013]. Disponível: ojs.c3sl.ufpr.br/ ojs/index.php/cogitare/article/download/27889/18497

13. Brüggemann $\mathrm{OM}$, Oliveira ME, Martins HEL, Alves MC, Gayeski ME. A inserção do acompanhante de parto nos serviços públicos de saúde de Santa Catarina, Brasil. Esc. Anna Nery. 2013;17(3):432-8.

14. Santos LFN, Santos LMS, Paiva MS, Barbosa TS, Oliveira V. O acompanhante no processo parturitivo: $\mathrm{O}$ que pensam as puérperas? In: VI Congresso Brasileiro de enfermagem Obstétrica e Neonatal; Qualificação da Atenção e dos Recursos Humanos de Enfermagem em Saúde da Mulher e do Recém-nascido, 2009. Teresina(PI): ABEn; 2003.

15. Oliveira ASS, Rodrigues DP, Guedes MVC, Felipe GF, Galiza FT, Monteiro LC. O acompanhante no momento do trabalho de parto e parto: percepção de puérperas. Cogitare enferm. 2011;16(2):247-53.

16. Teles MRT, Pitombeira HCS, Oliveira AS, Freitas LV, Moura ERF, Damasceno AKC. Parto com acompanhante e sem acompanhante: a opinião das puérperas. Cogitare enferm. [Internet] 2010;15(4) [acesso em 23 
out 2013]. Disponível: ojs.c3sl.ufpr.br/ojs2/index.php/ cogitare/article/download/20366/13527

17. Oliveira EMF, Brito RS. Ações de cuidado desempenhadas pelo pai no puerpério. Esc. Anna Nery. [Internet] 2009;13(3) [acesso em 23 out 2013]. Disponível: http://dx.doi.org/10.1590/S141481452009000300020

18. Cardinali F, Aires LCP, Monticelli M, Correia DS, Mendes L, Alcântara MG. O acompanhante no alojamento conjunto da maternidade. Rev. Enferm. UFSM 2011;1(1):1-14.

19. Oliveira AS, Damasceno AKC, Moraes JL, Moreira KAP, Teles LMR, Gomes LFS. Tecnologias utilizadas por acompanhantes no trabalho de parto e parto: estudo descritivo. Online Braz J Nurs. 2014;13(1):36-45.

20. Perdomini FRI, Bonilha ALL. A participação do pai como acompanhante da mulher no parto. Texto Contexto Enferm. [Internet] 2011;20(3) [acesso em 14 ago 2013] Disponível: http://dx.doi.org/10.1590/ S0104-07072011000300004

21. Santos LM, Carneiro CS, Carvalho ESS, Paiva MS. Percepção da equipe de saúde sobre a presença do acompanhante no processo parturitivo. Rev Rene. 2012;13(5):994-1003. 